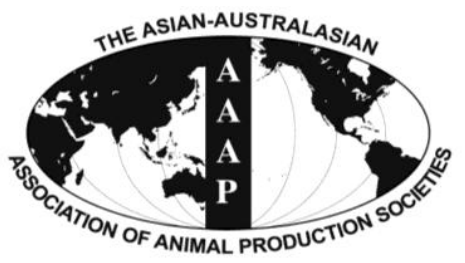

Asian-Aust. J. Anim. Sci.

Vol. 25, No. 11 : 1515-1520 November 2012

http://dx.doi.org/10.5713/ajas.2012.12351

www.ajas.info

pISSN 1011-2367 elSSN 1976-5517

\title{
DNA Polymorphism of Insulin-like Growth Factor-binding Protein-3 Gene and Its Association with Cashmere Traits in Cashmere Goats
}

\author{
Haiying Liu, Chao Liu, Guiqin Yang*, Hui Li, Jin Dai ${ }^{1}$, Yuyan Cong and Xuejian Li \\ College of Animal Science and Veterinary Science, Shenyang Agricultural University, Shenyang, 110866, China
}

\begin{abstract}
Insulin-like growth factor binding protein-3 (IGFBP-3) gene is important for regulation of growth and development in mammals. The present investigation was carried out to study DNA polymorphism by PCR-RFLP of IGFBP-3 gene and its effect on fibre traits of Chinese Inner Mongolian cashmere goats. The fibre traits data investigated were cashmere fibre diameter, combed cashmere weight, cashmere fibre length and guard hair length. Four hundred and forty-four animals were used to detect polymorphisms in the hircine IGFBP-3 gene. A 316-bp fragment of the IGFBP-3 gene in exon 2 was amplified and digested with HaeIII restriction enzyme. Three patterns of restriction fragments were observed in the populations. The frequency of $\mathrm{AA}, \mathrm{AB}$ and $\mathrm{BB}$ genotypes was $0.58,0.33$ and 0.09 respectively. The allelic frequency of the $\mathrm{A}$ and $\mathrm{B}$ allele was 0.75 and 0.25 respectively. Nucleotide sequencing revealed a $\mathrm{C}>\mathrm{G}$ transition in the exon 2 region of the IGFBP-3 gene resulting in R158G change which caused the polymorphism. Least squares analysis revealed a significant effect of genotypes on cashmere weight $(p<0.0001)$, cashmere fibre length $(p<0.001)$ and hair length $(p<0.05)$ of the animals. The effect of genotypes on cashmere fibre diameter was not statistically significant $(p>0.05)$. The animals of $A B$ and $B B$ genotypes showed higher cashmere weight, cashmere fibre length and hair length than the animals possessing AA genotype. These results suggested that polymorphisms in the hircine IGFBP-3 gene might be a potential molecular marker for cashmere weight in cashmere goats. (Key Words: Cashmere Goat, IGFBP-3 Gene, PCR-RFLP, Cashmere Traits)
\end{abstract}

\section{INTRODUCTION}

Cashmere fibre grown in goats (Capra hircus), is one of the finest and softest animal fibres, with an average diameter of $15 \mu \mathrm{m}$, and is used exclusively in luxurious textile products (McCarthy, 1998). World market demands still exceed the supply, so prices are consistently stable and much higher than for wool or mohair. The value of cashmere is determined largely by clean cashmere weight and fibre diameter with an increasing market premium for $15 \mu \mathrm{m}$ diameter and finer cashmere. The Inner Mongolian cashmere goat is one of the best breeds of cashmere goat in China and is an important source of income for Inner Mongolia region with the largest portion of income derived from cashmere (Bai et al., 2006). The Inner Mongolian

\footnotetext{
* Corresponding Author: Guiqin Yang. Tel: +86-24-88487156, Fax: +86-24-88487156, E-mail: guiqiny@ 126.com

1 Procurement Department, China Petroleum LONGWAY Engineering Project Management CO., LTD., Langfang, 065000, China.

Submitted Jun. 21, 2012; Accepted Aug. 3, 2012; Revised Aug. 21, 2012
}

cashmere goat is varied in production traits among individuals and flocks (Zhou et al., 2003). Therefore, the main objectives of the Inner Mongolian cashmere goat breeder are to breed cashmere goats for increased cashmere fleece weight with fine fibre diameter.

Insulin-like growth factors (IGFs) are the major polypeptides involved in the regulation of cell differentiation, growth, development and metabolism in mammals (Hossner et al., 1997). IGFs are critically involved in promoting hair growth by regulating cellular proliferation and migration during the development of hair follicles (Sun et al., 1999; Weger and Schlake, 2005a). Due to the key role of IGFs in hair growth and hair follicle development, the IGFs genes are considered as candidate genes for hair traits (Philpott et al., 1994). Insulin-like growth factor binding protein-3 (IGFBP-3) gene is a structural gene responsible for the multiple influences of IGFs system. It has been demonstrated to be predominantly expressed in cells of the dermal papilla in the human hair follicle (Batch et al., 1996). In the mouse, IGFBP-3 protein has been localized to the zone of follicular apoptosis at the 
onset of the regression phase of the hair cycle (Botchkarev et al., 2001). Based on expression patterns, IGFBP-3 might also play a major role in mammalian skin and hair growth (Schlake, 2005; Weger and Schlake, 2005b). Polymorphisms have been described in sheep (Kumar et al., 2006; Ali et al., 2009) and goats (Lan et al., 2007a, 2007b), and association of the IGFBP-3 genotypes with production traits has been reported (Lan et al., 2007b; Li et al., 2008; Shen et al., 2008). However, polymorphisms of IGFBP-3 gene association with cashmere production traits in cashmere goats has not been reported so far. The present investigation was conducted to study DNA polymorphism of IGFBP-3 gene in cashmere goats and to explore its possible association with cashmere traits in Inner Mongolian cashmere goats.

\section{MATERIALS AND METHODS}

\section{Animals}

The animals used in this study consisted of 414 Inner Mongolia cashmere female goats from 24 selected sires. All goats were ear tagged at birth with both colored and aluminium tags and their pedigree was recorded. The goats were raised in the breeding cashmere goat farm in the southwest of the Inner Mongolia region of China. All animals were kept exclusively in a desert pasture all year round with the similar rearing and feeding conditions.

\section{Genomic DNA preparation}

Blood samples were collected by venepuncture into 10 ml EDTA vacutubes. The blood samples were stored frozen at $-20^{\circ} \mathrm{C}$. DNA was isolated from $5 \mathrm{ml}$ of thawed blood using the method of Sambrook et al. (1989). The DNA samples were diluted to $100 \mathrm{ng} / \mu \mathrm{l}$ in $10 \mathrm{mM}$ Tris- $\mathrm{HCl} \mathrm{pH} 8$ ready for using in $\mathrm{PCR}$ and stored at $-20^{\circ} \mathrm{C}$.

\section{Phenotypic data collection}

The fibre data including combed cashmere weight, cashmere fibre length and guard hair length, were collected from farm records. Moulted cashmere was harvested once a year by combing in late April, and weighed using an electronic scale. Prior to combing, cashmere and guard hair length were measured at the same side of the shoulder using a steel rule without stretching the fibre. Cashmere and hair length were measured to the nearest $0.1 \mathrm{~cm}$. Patch samples of $10 \mathrm{~cm}^{2}$ moulted cashmere on the side of the shoulder were obtained before combing. Hairs in the samples of moulted cashmere were separated and the cashmere samples were washed in ether solution to remove contaminants such as soil and grease. The cashmere fibre diameter was measured using an Auda 2000 optical wool fiber gauging instrument (Shenaoda Technology Company,
Shijiazhuang, China) taking the mean from 1,000 fibres per animal. Measurements were performed by the Wool Analysis Laboratory of Liaoning Cashmere Breeding Center.

\section{PCR amplification and RFLP analysis}

PCR was performed to amplify a 316-bp fragment from exon 2 of IGFBP-3 gene using forward (5'-GAA ATG GCA GTG AGT CGG-3') and reverse (5'-TGG GCT CTT GAG TAA TGG TG-3') primers as described by Lan et al. (2007a). The nucleotide sequencing of the amplified product of IGFBP-3 gene was performed for cashmere goats and identified in the IGFBP-3 DNA sequence (NCBI GenBank accession no. EF203226.1). For amplification, $25-\mu \mathrm{l}$ PCR volume included $10 \mathrm{pmol}$ of each primer, 0.2 $\mathrm{mM}$ dNTP, $1.5 \mathrm{mM} \mathrm{MgCl} 2,2.5 \mu \mathrm{l}$ of $10 \times$ PCR assay buffer, 80 to $100 \mathrm{ng}$ of genomic DNA as template and 0.5 U Taq DNA polymerase (Dingguo Biotechnology Company, Beijing, China). The PCR protocol was $94^{\circ} \mathrm{C}$ for $5 \mathrm{~min}$ followed by 35 cycles of $94^{\circ} \mathrm{C}$ for $45 \mathrm{~s}$, annealing $61^{\circ} \mathrm{C}$ for $45 \mathrm{~s}$, and $72^{\circ} \mathrm{C}$ for $1 \mathrm{~min}$ and a final extension at $72^{\circ} \mathrm{C}$ for $10 \mathrm{~min}$.

Aliquots of $20 \mu \mathrm{l}$ PCR products of IGFBP-3 gene were digested with $10 \mathrm{U}$ HaeIII (TaKaRa biotechnology Biotechnology Co. LTD, Dalian, China) for $5 \mathrm{~h}$ at $37^{\circ} \mathrm{C}$ following the supplier's directions. The digested products were detected by electrophoresis in $3.0 \%$ agarose gel stained with ethidium bromide.

\section{DNA sequencing}

The PCR products of individuals that showed different conformation patterns were purified using the DNA Fragment Quick Purification/Recover Kit (Dinggou Biotechnology Company, Beijing, China), and cloned using pGEM-T Easy Vector Kit (Promega, Madison, WI, USA), then sequenced using an 3730 sequencer (Applied Biosystems 3730xl DNA Analyzer).

\section{Statistical analysis}

All data were subjected to general linear models analysis using the SAS software package (version 8.2). The mixed linear model was as follows:

$$
\mathrm{Y}_{\mathrm{ijkl}}=\mu+\mathrm{G}_{\mathrm{i}}+\mathrm{Y}_{\mathrm{j}}+\mathrm{A}_{\mathrm{k}}+\mathrm{S}_{\mathrm{l}}+\mathrm{e}_{\mathrm{ijkl}}
$$

Where $Y_{\mathrm{ijkl}}$ is an observation of the dependent variable (cashmere fibre diameter, combed cashmere weight, cashmere fibre and guard hair length); $\mu$ is the population mean for the variable; $G_{i}$ is the fixed effect of $i^{\text {th }}$ genotype ( $i$ $=1(A A), 2(A B), 3(B B)) ; Y_{j}$ is the fixed effect of $j^{\text {th }}$ year $(j$ $=1,2, \ldots, 8) ; \mathrm{A}_{\mathrm{k}}$ is the fixed effect of $\mathrm{k}^{\text {th }}$ age $(\mathrm{k}=1,2, \ldots$, 8); $S_{1}$ is the random effect of $1^{\text {th }}$ sire and $e_{i j k l}$ is the random 
residual term. Comparisons were made using least square means by Tukey options. The allele and genotype frequencies were calculated and Hardy-Weinberg equilibrium was tested by comparing expected and observed genotype frequencies using a Chi-square test.

\section{RESULTS}

\section{The analysis of polymorphism}

A $316 \mathrm{bp}$ of amplified product was obtained by PCR amplification. In the present investigation, the PCR products from all the animals studied revealed patterns of restriction fragments after digestion with HaeIII restriction enzyme. The pattern of sizes 264, 44 and 8 bp fragments was assigned as AA genotype; pattern of 195, 69, 44 and 8 bp fragments as BB genotype and pattern of 264, 195, 69, 44 and 8 bp fragments as $A B$ genotype (Figure 1). Sequence analysis of A and B allele of this study reveals a transition $\mathrm{C}>\mathrm{G}$ at nucleotide 69 of the amplified product (Figure 2). This mutation caused a missense mutation (Arg $>$ Gly) in exon 2 of the gene, which was the cause of the observed polymorphism and detected by HaeIII-RFLP in Inner Mongolia cashmere goats.

\section{Gene and genotype frequency}

The frequency of genotypes and alleles are shown in

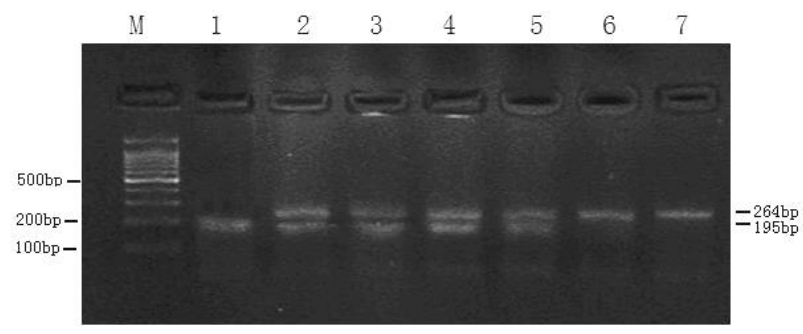

Figure 1. Representative HaeIII restriction fragment pattern of 316 bp IGFBP-3 gene fragment in cashmere goats. Lane M, molecular size marker (100 bp DNA ladder); Lanes 1: BB genotype (195, 69, 44 and 8 bp); Lane 2-5: AB genotype (264, 195, 69, 44 and 8 bp); Lane 6 and 7: AA genotype (264, 44 and 8 bp).

Table 1. The allelic frequency of the A and B allele in the population $(n=414)$ was 0.75 and 0.25 respectively. The data revealed that the mutation homozygotes (BB) are present at low frequencies in the population. The $x^{2}$ test showed that the genotype frequencies were in agreement with Hardy-Weinberg equilibrium in the population $(\mathrm{p}>0.05)$.

\section{Association between genotypes and fibre traits}

The genotype-wise least squares mean values along with the standard error for various traits in the population are given in Table 2. The analysis revealed significant

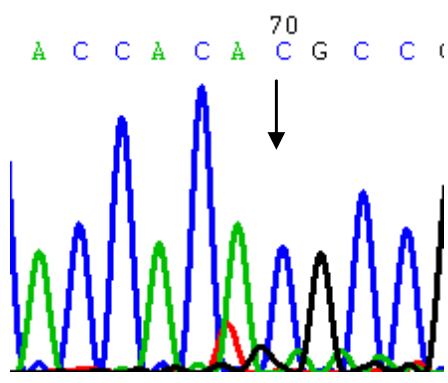

(b)

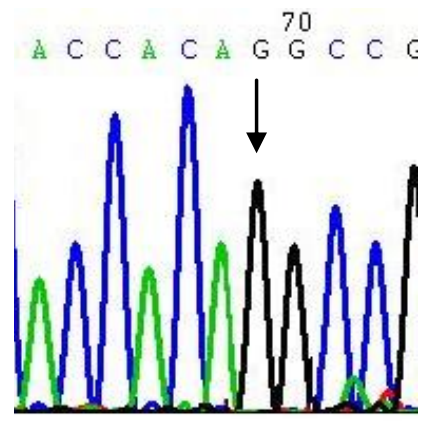

(c)

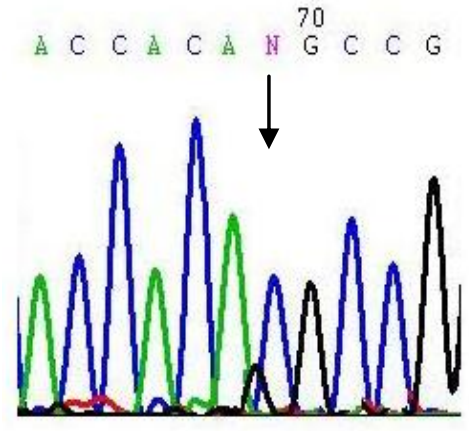

(d)

Figure 2. Nucleotide sequence comparison of the PCR products in Cashmere goat; (a) BLAST results of the nt sequence of three genotypes in this study with nt sequence in GenBank; (b) nt sequence of genotype AA (arrow's position is consistent with nt sequence in GenBank); (c) and (d) nt sequence of genotype AB and BB (the arrow points to the mutation site). 
Table 1. Genotype and allele frequencies of hircine IGFBP-3 gene

\begin{tabular}{|c|c|c|c|c|c|c|c|}
\hline \multirow{2}{*}{ Category } & \multicolumn{3}{|c|}{ Genotypes } & \multicolumn{2}{|c|}{ Alleles } & \multirow{2}{*}{$x^{2}$} & \multirow{2}{*}{$\mathrm{p}$} \\
\hline & AA & $\mathrm{AB}$ & $\mathrm{BB}$ & A & B & & \\
\hline No. animals & 243 & 135 & 36 & 621 & 207 & 2.35 & 0.1255 \\
\hline Frequency (\%) & 58.70 & 32.61 & 8.69 & 75.00 & 25.00 & & \\
\hline
\end{tabular}

association of the HaeIII genotypes with the cashmere weight $(\mathrm{p}<0.0001)$, cashmere fiber length $(\mathrm{p}<0.001)$ and hair length $(\mathrm{p}<0.05)$, but not with cashmere fibre diameter ( $>00.05$ ). Animals with $\mathrm{AB}$ and $\mathrm{BB}$ genotype were higher in cashmere weight than those with AA genotype with the mean difference of over 50 grams. The animals of $\mathrm{AB}$ and $\mathrm{BB}$ genotype had 0.21 or $0.24 \mathrm{~cm}$ longer cashmere length than the animals of AA genotype $(\mathrm{p}<0.001)$. Animals belonging to $\mathrm{AB}$ and $\mathrm{BB}$ genotype were longer by 0.66 and $1 \mathrm{~cm}$ than the animals of AA genotype in hair length $(\mathrm{p}<0.05)$. Genotypes with $B$ allele had significantly increased cashmere weight, cashmere length and hair length.

\section{DISCUSSION}

IGFBP-3 is a structural gene of IGFs system which is an important regulator in hair growth and hair follicle biology. There have been previous reports of IGFBP-3 gene expression during the hair cycle, which may imply a role of IGFBP-3 in the process of hair growth (Weger and Schlake, 2005a; Weger and Schlake, 2005b). In the human, IGFBP-3 is predominantly expressed in the dermal papilla hair follicle (Batch et al., 1996), and reports reveal the capability of keratinocytes to produce IGFBP-3 (Wraight et al., 1994). In the mouse, IGFBP-3 protein has been localized to the zone of follicular apoptosis at the onset of the regression phase of the hair cycle (Botchkarev et al., 2001), and the expression dramatically increases with the onset of catagen (Schlake et al., 2004). In the murine hair cycle, it has confirmed that IGFBP-3 gene activity occurs in dermal papilla cells of hair-producing follicles (Weger and Schlake, 2005a). Shen et al. (2008) reported polymorphism of IGFBP-3 gene was associated with wool traits in Merino sheep. Therefore, IGFBP-3 gene may be candidates for cashmere QTLs. However, no report of association study of IGFBP-3 genotypes with cashmere traits is available in the literature. Based on the reports from human, mouse and sheep, IGFBP-3 might also play a major role on cashmere growth.
In the current study, three genotypes and two alleles were identified by HaeIII endonuclease digestion (Figure 1) and sequencing showed a transition $\mathrm{C}>\mathrm{G}$ of the IGFBP-3 gene (Figure 2), which supports previous research (Lan et al., 2007a). The results revealed that the genotypes AA and $\mathrm{AB}$ were predominant in Inner Mongolian cashmere goats, the frequency being $58.7 \%$ and $32.6 \%$ respectively. The A and $\mathrm{B}$ allele frequencies were $75 \%$ and $25 \%$ respectively. The frequency of each genotype detected in our research was similar to the results of Lan et al. (2007a) in Inner Mongolia White cashmere goats. The distribution of allele and genotype frequencies in our sample was in accord with the Hardy-Weinberg equilibrium $\left(x^{2}=2.35, \mathrm{p}>0.05\right)$ indicating that the locus is under panmixia random mating. Similar to the present findings, polymorphism was also reported in dairy goat (Xinong Sannen, Laoshan, Guanzhong) and Inner Mongila White Cashmere breeds (Lan et al., 2007a). No polymorphism was detected by HaeIII-RFLP in Guizhou White, Leizhou and Shaannan White breeds of meat goat (Lan et al., 2007a), which leads us to believe that the IGFBP-3 gene varies considerably in different breeds. The differences in alleles and genotypes of IGFBP-3 locus among dairy, wool and meat goat in Chinese native breeds is possibly due to long-term artificial fertilization and selection towards different production options.

The current results are the first to reveal that the HaeIII polymorphisms of IGFBP-3 are associated with cashmere weight, cashmere length and hair length (Table 2). The goats with genotypes $\mathrm{AB}$ and $\mathrm{BB}$ had over $8 \%$ higher cashmere weight than genotype AA. Therefore, the genotype BB may be the most advantageous genotype for cashmere weight. Interestingly, the polymorphism was not associated with variation in cashmere fibre diameter. The strong association of polymorphism with cashmere weight but not cashmere fibre diameter suggests that these traits are controlled by different genes and may be selected for separately (Adelson et al., 2002). Higher cashmere weight

Table 2. Least squares mean values for cashmere fibre traits in Inner Mongolian cashmere goat

\begin{tabular}{lcccc}
\hline Genotype & Fibre diameter $(\mu \mathrm{m})$ & Cashmere weight $(\mathrm{g})$ & Cashmere length $(\mathrm{cm})$ & Hair length $(\mathrm{cm})$ \\
\hline AA & $14.98 \pm 0.11$ & $637.75 \pm 11.99^{\mathrm{A}}$ & $5.80 \pm 0.10^{\mathrm{Aa}}$ & $17.27 \pm 0.65^{\mathrm{a}}$ \\
AB & $15.12 \pm 0.15$ & $692.39 \pm 13.96^{\mathrm{B}}$ & $6.04 \pm 0.11^{\mathrm{Bb}}$ & $17.93 \pm 0.66^{\mathrm{b}}$ \\
BB & $15.03 \pm 0.26$ & $698.82 \pm 20.70^{\mathrm{B}}$ & $6.03 \pm 0.14^{\mathrm{ABb}}$ & $18.28 \pm 0.81^{\mathrm{b}}$ \\
\hline
\end{tabular}

Mean within a column with no common superscript capital letters differed significantly $(\mathrm{p}<0.01)$ and mean within a column with no common superscript lowercases differed significantly $(\mathrm{p}<0.05)$. 
may be related to longer cashmere length or higher primary secondary to primary follicle ratio $(\mathrm{S} / \mathrm{P})$. This is important and indicates cashmere goats may be selected to produce higher cashmere weights and finer cashmere fibre at the same time (Liu et al., 2011).

The $\mathrm{C}>\mathrm{G}$ mutation identified a missense mutation $\mathrm{R} 158 \mathrm{G}$, which resulted in charge change from positive charge to zero. The HaeIII polymorphism of IGFBP-3 gene significantly associated with cashmere weight and fibre length, indicating that they could be important functional sites for IGFBP-3 and further studies are needed to investigate it. Investigations are required on the gene function at the cellular level and its interactions with other candidate genes.

\section{CONCLUSION}

The IGFBP-3 gene has shown a significant effect on cashmere weight, cashmere fibre length and hair length. The presence of the $\mathrm{B}$ allele in the cashmere goats significantly improves their cashmere weight, fibre length and hair length. Although confirmation of our data requires further analysis on other herds, the association of genotypes with cashmere growth performance is a very interesting and potentially important finding.

\section{ACKNOWLEDGEMENTS}

This project was supported by NSFC (No. 31101734) and Doctor Initial Fund of Liaoning province (No. 20101097), P. R. China. We thank Saoqing Liu, Yongbing Zhang and other staff at the Inner Mongolian cashmere goats breeding farm for the collection of blood samples and production traits data. We also thank the faculty of the Liaoning cashmere breeding center for measurement of cashmere fibre diameter.

This work was supported by NSFC (No. 31101734) and Doctor Initial Fund of Liaoning province (No. 20101097), China.

\section{REFERENCES}

Adelson, D. L., D. E. Hollis and G. H. Brown. 2002. Wool fibre diameter and follicle density are not specified simultaneously during wool follicle initiation. Aust. J. Agric. Res. 53:10031009.

Ali, B. A., A. A. EL-Hanafy and H. H. Salem. 2009. Genetic biodiversity studies on IGFBP-3 gene in Egyptian sheep breeds. Biotechnol. Anim. Husb. 25:101-109.

Bai, J. Y., Q. Zhang, J. Q. Li, Er-Ji Dao and X. P. Jia. 2006. Estimates of genetic parameters and genetic trends for production traits of Inner Mongolian White cashmere goat. Asian-Aust. J. Anim. Sci. 19:13-18.

Batch, J. A., F. A. Mercuri and G. A. Werther. 1996. Identification and localization of insulin-like growth factor-binding protein (IGFBP) messenger RNAs in human hair follicle dermal papilla. J. Investig. Dermatol. 106:471-475.

Botchkarev, V. A., E. A. Komarova, F. Siebenhaar, N. V. Botchkareva, A. A. Sharov, P. G. Komarov, M. Maurer, A. V. Gudkov and B. A. Gilchrest. 2001. p53 Involvement in the control of murine hair follicle regression. Am. J. Pathol. 158: 1913-1919.

Hossner, K. L., R. H. McCusker and M. V. Dodson. 1997. Insulinlike growth factors and their binding proteins in domestic animals. Anim. Sci. 64:1-15.

Kumar, P., V. Choudhary, K. G. Kumar, T. K. Bhattacharya, B. Bhushan, A. Sharma and A. Mishra. 2006. Nucleotide sequencing and DNA polymorphism studies on IGFBP-3 gene in sheep and its comparison with cattle and buffalo. Small Rumin. Res. 64:285-292.

Lan, X. Y., C. Y. Pan, H. Chen, C. Z. Lei, S. Q. Liu, Y. B. Zhang, L. J. Min, J. Yu, J. Y. Li, M. Zhao and S. R. Hu. 2007a. The HaeIII and XspI PCR-RFLPs detecting polymorphisms at the goat IGFBP-3 locus. Small Rumin. Res. 73:283-286.

Lan, X. Y., C. Y. Pan, H. Chen, M. Zao, J. Y. Li, J. Yu, C. L. Zhang, C. Z. Lei, L. S. Hua and X. B. Yang. 2007b. The novel SNPs of the IGFBP3 gene and their associations with litter size and weight traits in goat. Arch. Tierz., Dummerstorf. 50:223-224.

Li, M. Y., L. Li, L. J. Min and J. M. Wang. 2008. Genetic analysis of IGFBP-3 gene and its association with economic traits in goats. Acta Veterinariaet Zootechnica Sinica. 39:1647-1653.

Liu, H. Y., C. W. Yue, W. Zhang, X. P. Zhu, G. Q. Yang and Z. H. Jia. 2011. Association of the KAP 8.1 gene polymorphisms with fibre traits in inner mongolian cashmere goats. AsianAust. J. Anim. Sci. 24:1341-1347.

McCarthy, B. J. 1998. Specialty animal fibres. Textiles 1:6-8.

Philpott, M. P., D. Sanders, G. E. Westgate and T. Kealey. 1994. Human hair growth in vitro: a model for the study of hair follicle biology. J. Dermatol. Sci. 7:S55-72.

Sambrool, J., E. F. Fritsch and T. Maniatis. 1989. Molecular Cloning: a laboratory manual. 2nd ed. N.Y., Cold Spring Harbor Laboratory, Cold Spring Harbor Laboratory Press.

Schlake, T., M. Beibel, N. Weger and T. Boehm. 2004. Major shifts in genomic activity accompany progression through different stages of the hair cycle. Gene Expr. Patterns 4:141152.

Schlake, T. 2005. Segmental Igfbp5 expression is specifically associated with the bent structure of zigzag hairs. Mech. Dev. 122:988-997.

Shen, M., W. J. Wang, Y. L. Yang, S. Q. Gan, Q. H. He, Y. S. Zhang, J. H. Wang, C. P. Ma, Z. S. Liu, S. R. Liu and N. Li. 2008. A novel polymorphism of IGFBP-3 gene and its relationship with several wool traits in Chinese Merino sheep. Hereditas. 30:1182-1186.

Su, H. Y., J. G. Hickford, R. Bickerstaffe and B. R. Palmer. 1999. Insulin-like growth factor 1 and hair growth. Dermatol. Online J. 5:1.

Weger, N. and T. Schlake. 2005a. Igf-I signalling controls the hair growth cycle and the differentiation of hair shafts. J. Invest. Dermatol. 125:873-882.

Weger, N. and T. Schlake. 2005b. Igfbp3 modulates cell proliferation in the hair follicle. J. Invest. Dermatol. 125:847849. 
Wraight, C. J., M. M. Murashita, V. C. Russo and G. A. Werther. 1994. A keratinocyte cell line synthesizes a predominant insulin-like growth factor-binding protein (IGFBP- 3) that modulates insulin-like growth factor-I action. J. Invest. Dermatol. 103:627-631.
Zhou, H. M., D. Allain, J. Q. Li, W. G. Zhang and X. C. Yu. 2003. Effects of non-genetic factors on production traits of Inner Mongolia cashmere goats in China. Small Rumin. Res. 47:8589. 